\title{
RESPONSE OF TUNISIAN DURUM AND COMMON WHEAT CULTIVARS TO POWDERY MILDEW UNDER NATURAL INFECTION
}

\author{
Imran HAMMAMI*, Dhoha MANSOURI, Neila RASSAA, Soumaya KHALDI, Mohamed EL GAZZAH \\ Université de Tunis El Manar, Faculté des sciences de Tunis, Laboratoire de Biodiversité, \\ Biotechnologies et changements climatiques. Campus universitaire. El Manar. Tunis. (Tunisie). \\ *Corresponding author: imran.hammami@fst.rnu.tn
}

Received : 11.02.2014

\begin{abstract}
Cereal production is an important component of agriculture. Powdery mildew (Erysiphe graminis f. sp tritici Em. Marchal), caused by Blumeria graminis (DC.) E.O Speerf. sp. tritici (Bgt), which is one of the most worldwide devastating diseases of durum and common wheat specially in Tunisia. Several works have discussed plant resistance to mildew and its potential risks but, it was neglected or no study was reported for that in Tunisia. There is an increasing need for studies that address the potential side effects of mildew to different wheat cultivars and their outcome and behave via disease criteria. This study focuses to compare the behave of ten Tunisian wheat cultivars to powdery mildew under field conditions during two successive cropping seasons 2011-2013. Using the 5 disease criteria (infected leaf number, pustules per stem and per leaf, number of spores produced per pustule and AUDPC "Area Under the Disease Progress Curve", based on pustules per leaf) to investigate the plant disease resistance, specially the AUDPC parameter, durum wheat showed susceptibility to natural infection of powdery mildew specially the cultivar Souabaa Eljia with mean AUDPC value of 583.8, while common wheat, the cultivar Hydra, showed resistance with mean AUDPC value of 52.1, while, the improved durum cultivars Nasr and Karim showed an intermediate reaction. Principal Components Analysis (PCA) showed that the variables were grouped in two principal components that explained $76.65 \%$ of the total variance. The projection of the point-cloud representing the populations on the plan formed by the principal components «Fact.1» $(49.65 \%)$, in abscissa, and «Fact.2» $(27 \%)$ in ordinate, permitted to distribute the accessions in several groups. Two common wheat cultivars (Hydra and Bysra) showed on one hand a high level of resistance to Bgt and on other hand this fungus behaves differently on these cultivars via the conidia production. The cluster analysis suggested that these two cultivars are genetically similar, but the PCA distribute each one in a distinct single group. Hydra affect all the component of resistance tested and seems more efficient than Bysra.
\end{abstract}

Keywords: Powdery mildew, Wheat, Resistance, Tunisia

\section{INTRODUCTION}

Wheat is a foremost crop contributing prominently to the nutrient furnish of the global population and also a very adaptable crop (Mladenov et al., 2012); it shows large adjustment to various agro-ecological environment (Pena, 2007). In Tunisia, breeding cereals was initiated early in the $20^{\text {th }}$ century. From 1950 to 1968 , new parents in crosses introduced were used to improve precocity, fertility and disease resistance. Then the grain improvement was characterized by the introduction, testing and use inbreeding high-yielding germplasm mostly from the International Maize and Wheat Improvement Center; other varieties of durum and common wheat were selected from some Mexican germplasm (Maamouri and El Faleh, 1983). Most of these wheat varieties were resistant for major diseases (Daaloul, 1986). Cereal production has always been an important component of Tunisian agriculture. Cereals are sown every year in Tunisia between October and December on about 1.5 million hectares. Durum wheat is the major crop and the most widely cultivated cereal in Tunisia (Latiriet al., 2010).

Powdery mildew, caused by $B g t$, is one of the most worldwide devastating diseases of durum and common wheat (Zhang et al., 2008; Filippoet al., 2012), particularly in areas, such as the Mediterranean basin, where epidemiological factors are favorable (De Curtis et al., 2007). Bgt is an obligate biotrophic fungus and comprises as a species specialized physiological forms (forma specials, f.sp.) based on strict host specialization (Friedrich et al., 2010). For susceptible wheat cultivars, the disease can completely cover plant surfaces under favorable climatic conditions, occurring mostly on the upper leaf surface (Na Liu et al.,2012). This disease has caused several yield losses ranging from 13 to $40 \%$ (Griffey et al., 1993). Whereas complete resistance has 
been a major weapon used by plant breeders to control $B g t$, the generally race-specific and hence non-durable nature of this resistance has shifted the focus to race-nonspecific partial resistance (Kinane and Jones, 2000). The characteristic disease symptoms caused by powdery mildew fungi comprise whitish velvety pustules that cover leaves, stems, and even ears of infected plants (Ruth and Ralph, 2008).

The use of varieties that have a high degree of stability of performance and potential yields under rained and supplemental irrigation is of great importance. Many researchers are often required to perform stability analyzes or genotype-environment interaction using different approaches. This interaction can be exploited to develop varieties with specific adaptation (Rezgui et al., 2000). According to our knowledge, a few or no studies were interested to the potential intensity of Tunisian wheat resistance to the mildew disease. The aim of the present work was to assess types and levels of powdery mildew resistance of durum and common wheat cultivars registered in Tunisia.

\section{MATERIALS and METHODS}

Ten wheat cultivars were studied in this survey, six durum wheat and four common wheat (Table 1). Each cultivar was represented by 15 to 20 plants to characterize reaction to powdery mildew under field conditions. Survey was carried out during two successive cropping season 2011-2013. Plots consisted of two rows, $1 \mathrm{~m}$ long and $80 \mathrm{~cm}$ a part, for each cultivar, they were arranged in three randomize complete block at the experimental station of the Faculty of Science, Campus, Tunis, Tunisia (36 $49^{\prime} 32.88^{\prime}, \mathrm{N}, 1^{\circ} 08^{\prime} 38.49^{\prime}$ ' E, elevated $\left.69 \mathrm{~m}\right)$. Temperature, precipitation and insolation were measured during the two cropping seasons (Figure1).

Table 1.Description of wheat varieties used in resistance tests to powdery mildew.

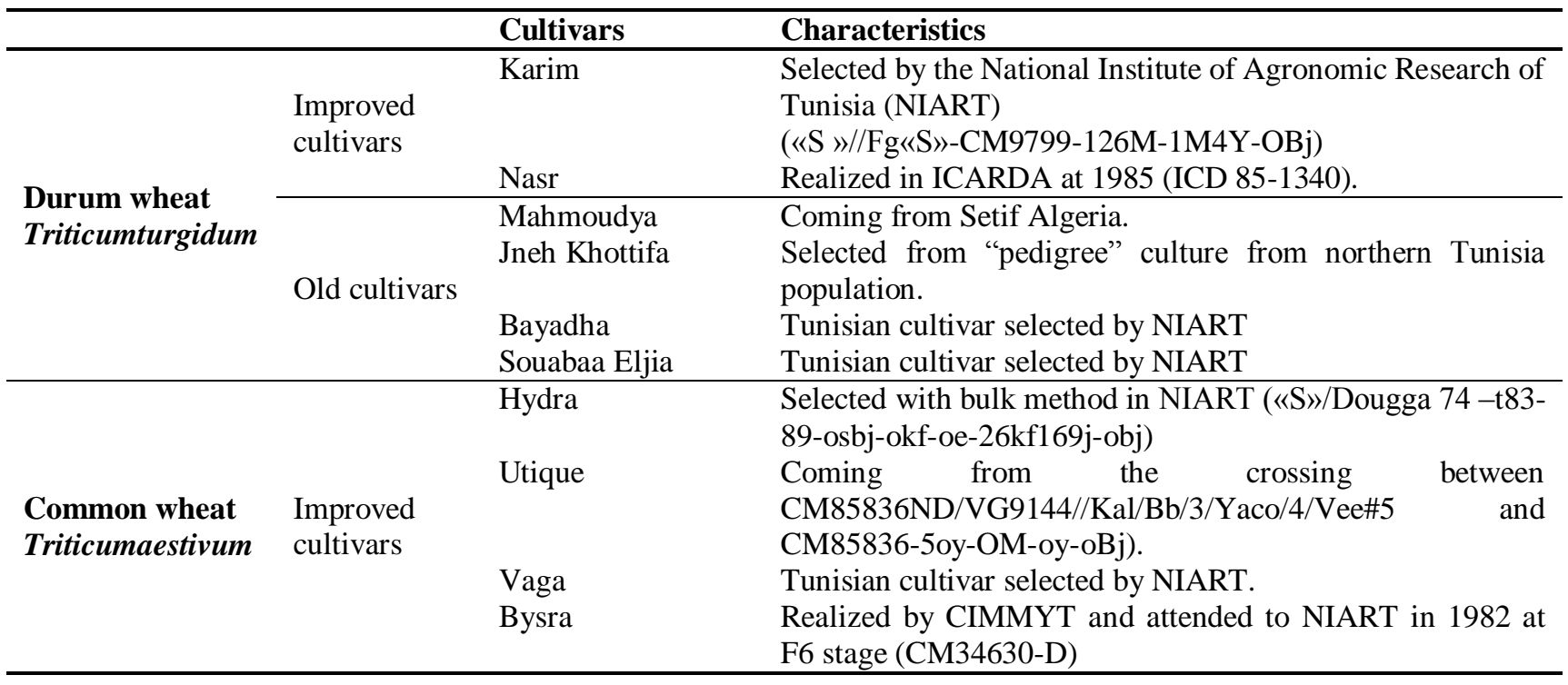

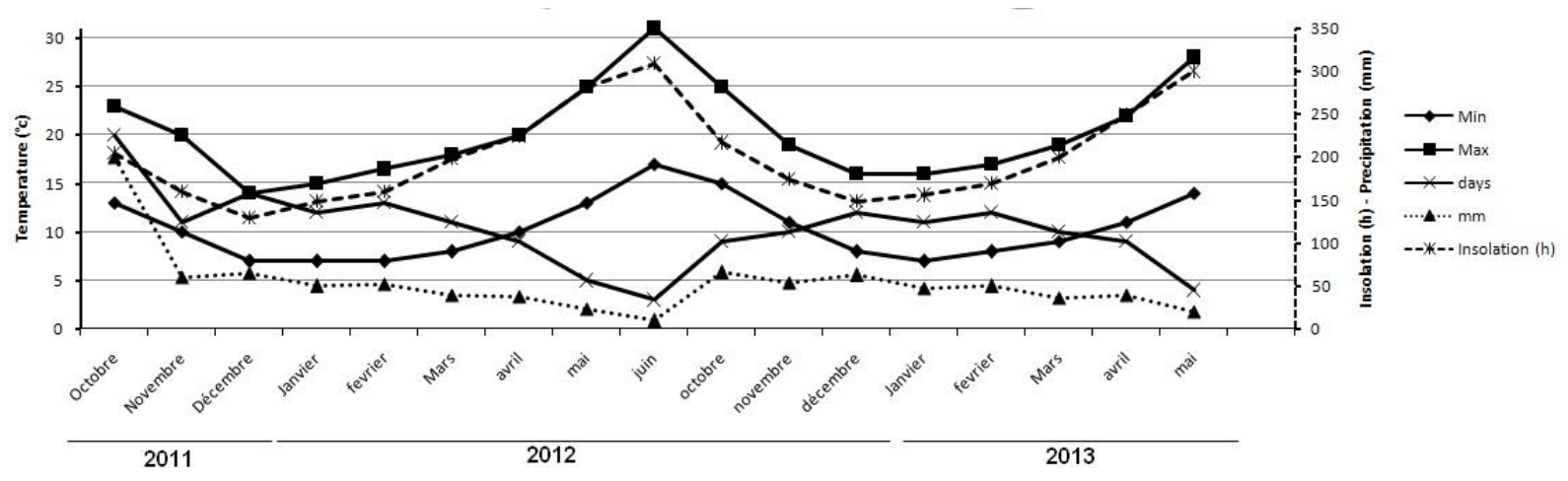

Figure 1.Temperature, precipitation and insolation during the two cropping season 
Disease was assessed 8 times from stem elongation to late milk development, with 7 days between notations. Disease resistance was measured with 5 disease criteria: Pustule per stem, pustule per leaf, infected leaves, conidia per pustule and the area under the disease progress curve (AUDPC) that was calculated as (Hammami et al., 2007):

$$
\text { AUDPC }=0.5 \Sigma\left(\mathrm{t}_{i+1}-\mathrm{t}_{i}\right)\left(\mathrm{y}_{i+1}+\mathrm{y}_{i}\right),
$$

where the day of the $i$ th reading is indicated by $t_{i}$ with $i$ $=1$ for the first reading, $i=2$ for the second etc., and where $y_{i}$ is the mean number of pustule per leaf at the $i$ th reading. Treatment means were compared using Duncan's multiple range tests.

At the eighth notation, 5 single pustule isolates of $B g t$ were collected from the most infected leaf. Spores of each single pustule were suspended in $5 \mathrm{ml}$ sterile distilled water. Spores number per $\mathrm{ml}$ was determined using a Malassez cell. The average of the 5 pustule isolates determinations was recorded.

\section{Statistical analysis}

Data were analyzed by the basic module of STATISTICA 6.0 (Statsoft, 2001). Means, standard errors, and variance were calculated for all data, and per plot. Analyses of variance (ANOVA) were computed for all continuous variables to indicate the significance between accessions for the various traits.

\section{Principal components analysis}

The criteria: AUDPC, pustule per stem and conidia per pustule were applied to the principal components analysis (PCA). The number of infected leaves was non-significant between cultivars (Fig. 2). The PCA is a common technique that permits to visualize the data and to find others true measurement of a sampling. The PCA generates a set of new variables (axes), of new linear combinations of those original, so that the maximal value of variance contained in the sampling (information) is concentrated in the first main components (Meloun et al., 1992).

\section{RESULTS}

\section{Area Under the Disease Progress Curve (AUDPC)}

All durum wheat cultivars except Ttg3 showed the highest AUDPC values. The most susceptible cultivar among the registered ones by maximal AUDPC was «Souabaa Eljia», with a mean value of 583.8. In contrast, common wheat showed the lowest AUDPC values except for «Vaga»which demonstrated a mean AUDPC value of 289.4. «Hydra» and «Bysra» were the most resistant cultivars. AUDPC wean values was 52.81 for «Hydra» and 52.1 for «Bysra»(Figure 2). The AUDPC values characterized conditions of year for powdery mildew development better than the other disease component.
«Souabaa Eljia» could be chosen as the susceptible check since it was heavily infected with the powdery mildew during the two cropping seasons. These results proved that the whole experimental period was characterized by heavy epidemic pressure, which enabled us to adequately evaluate the resistance level of the tested cultivars.

\section{Pustule per stem}

The durum wheat cultivar «Souabaa Eljia» showed a high pustule number per stem with a mean value of 23.22. However, the durum wheat cultivar «Mahmoudi» and «Jneh Khottifa» showed a reduced pustule number per stem with a mean value of 1.63 for «Mahmoudi» and 2.1 for «Jneh Khottifa». Three common wheat cultivars, «Hydra», «Utique» and «Vaga» showed a reduced pustule number per stemwith a mean value of 4.90, 2.42 and 1.57, respectively (Figure 2).

\section{Infected leaves}

This component was non-significant between cultivars. A slight difference was shown between durum wheat and common wheat cultivars. The highest numbers of infected leaves are shown in durum wheat cultivars, with a mean value of 4.2 for «Karim» 5 for «Nasr»; «Mahmoudi» showed inferior values with a mean value of 4.15. Overall common wheat cultivars showed a slight reduced number of infected leaves, with mean values of 3.53, 4 and 3.75 for «Hydra», Vaga» and «Bysra», respectively (Figure 2).

\section{Pustule per leaf}

The highest pustule number per leaf is shown in the durum wheat cultivar «Souabaa Eljia», with a mean value of 50.25. In contrast, the common wheat cultivar «Hydra» showed a mean value of 11.53 (Figure 2).

\section{Conidia per pustule}

The durum wheat cultivars «Mahmoudi» and «Souabaa Eljia» showed low number of conidia per pustule, with a mean value of $6 \times 10^{4}$ and $8.68 \times 10^{4}$, respectively; whereas, «Jneh Khottifa» showed high conidia production per pustule with a mean value of $17.5 \times 10^{4}$. The common wheat cultivar «Hydra»and «Vaga» showed reduced number of conidia per pustule, with a mean value of $8 \times 10^{4}$ and $7.14 \times 10^{4}$, respectively; whereas, «Bysra» showed high mean value of $27.75 \times 10^{4}$ (Figure 2).

Overall and basing on AUDPC parameter, durum wheat showed susceptibility to natural infection of powdery mildew specially the cultivar «Souabaa Eljia» while common wheat showed resistance specially the cultivar «Hydra» and «Bysra». The improved cultivars «Karim» and «Nasr » showed an intermediate reaction (Figure2). 


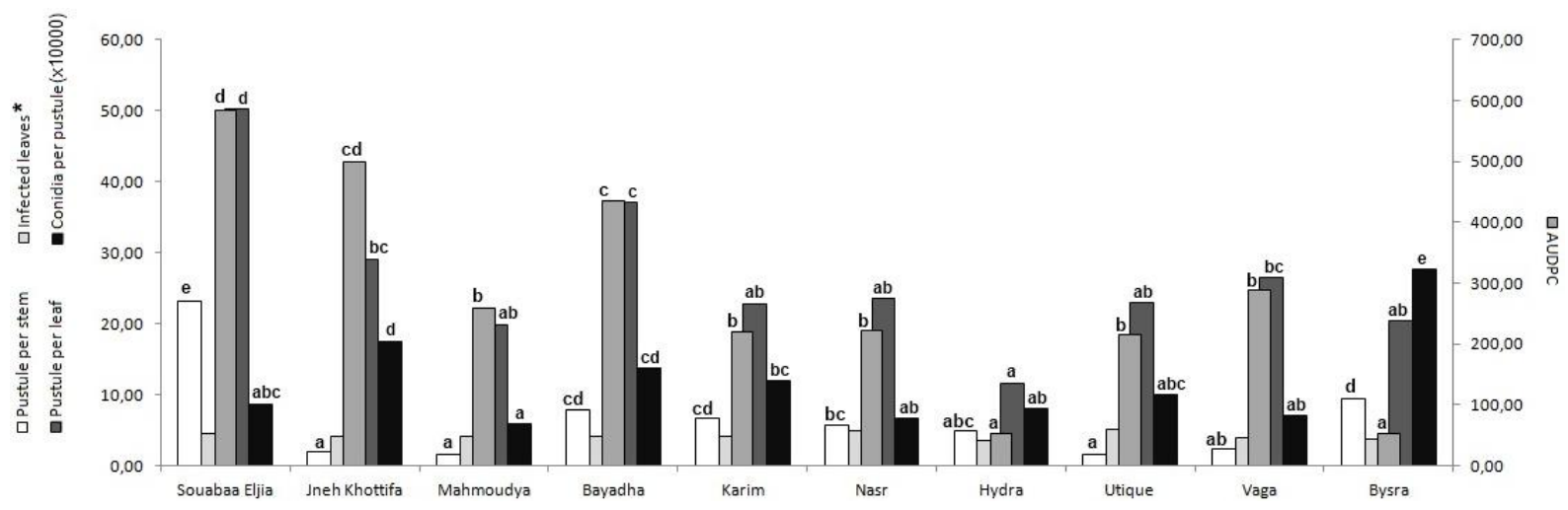

Figure 2.Mean values of five components of resistance (AUDPC, Pustule per stem, Pustule per leaf, Infected leaves and Conidia per pustule). Components mean values indicated with the same letter (s) are not significantly different. *The number of infected leaves was no- significant between all cultivars.

\section{Correlation}

Positive and significant correlations between components of resistance to powdery mildew were shown

between pustule per leaf and both, AUDPC and pustule per stem, with a correlation coefficient of 0.89 and 0.73 respectively (Table 2).

Table 2. Correlation coefficients between components of resistance to powdery mildew observed in ten local varieties.

\begin{tabular}{lcccc}
\hline & AUDPC & Pustule per stem & Infected leaves & Pustules per leaf \\
\cline { 2 - 5 } Pustule per stem & 0.43 & & & \\
Infected leaves & 0.25 & 0.03 & & \\
Pustules per leaf & $0.89^{* *}$ & $0.73^{*}$ & 0.28 & \\
Conidia per pustule & -0.16 & 0.09 & -0.35 & -0.033 \\
\hline
\end{tabular}

For each correlation $\mathrm{n}=86$. Correlations are denoted by ${ }^{*}(\mathrm{P} \leq 0.05) * *(\mathrm{P} \leq 0.01)$

\section{Principal components analysis}

To check the progression structuring of wheat infection by the powdery mildew, principal components analysis was done, using as parameters the AUDPC, the pustule per stem, the pustule per leaf and the infected leaves, at the different cultivars. Based on eigenvalues of the order of 0.8 as was suggested by George et al. (2005), the PCA grouped the variables into two components. These two principal components explained $76.65 \%$ of the total variance (Table 3 ).

Table 3.Eigenvalue, percentage variance accounted for and cumulative variance for the principal components.

\begin{tabular}{llll}
\hline & Eigenvalues & Percentage & Cumulative percentage \\
\hline Fact.1 & 2.4827 & $49.65 \%$ & $46.49 \%$ \\
Fact.2 & 1.3499 & $27 \%$ & $76.65 \%$ \\
\hline
\end{tabular}

The first component «Fact.1» (49.65\%) is correlated positively and tightly with the variables «AUDPC»«pustule per leaf», and «pustule per stem» and moderately correlated with the variable «infected leaves». The high values of this component (positive sense of the axis) represent the high symptoms of severity and an infection type characterizing the susceptibility of the populations (Table 4).
Table 4.Correlations between original variables and the principal components.

\begin{tabular}{lll}
\hline & Fact.1 & Fact.2 \\
\hline AUDPC & 0.8875 & -0.0324 \\
Pustule per stem & 0.7411 & 0.4151 \\
Infectedleaves & 0.4 & -0.6975 \\
Pustule per leaf & 0.9788 & 0.1381 \\
Conidia per pustule & -0.1663 & 0.819 \\
\hline
\end{tabular}

The second component «Fact.2» $(27 \%)$ is correlated positively and tightly with the variable «Conidia per pustule» and moderately correlated with «pustule per stem». This component is also correlated negatively and moderately with «infected leaves». Positive and negative values of this component represent a moderate severity of powdery mildew symptoms. This component means a moderate level of partial resistance in the positive sense and a high level of partial resistance in the negative sense of the axis. The new point coordinates representing the accessions on the new axes (Fact.1 and Fact.2) were calculated (Table 5). The projection of the cloud-point representing the accessions on the plan formed by the principal components Fact.1, in abscissa, and Fact.2 in ordinate, allowed to distribute the accessions in some groups (Figure 3, 4). 
Table 5.Absorption of the variability by four axes and their significance in relation to the variables for the whole population.

\begin{tabular}{lll}
\hline & Fact.1 & Fact.2 \\
\hline Souabaa Eljia & 2,2107 & 0,2708 \\
Jneh Khottifa & 0,2390 & $-0,0283$ \\
Mahmoudya & $-0,8044$ & 0,3848 \\
Bayadha & 1,0897 & $-0,2692$ \\
Karim & $-0,3536$ & $-0,1678$ \\
Nasr & $-0,3192$ & 1,2316 \\
Hydra & $-1,3308$ & $-0,4080$ \\
Utique & $-0,4112$ & 1,0516 \\
Vaga & $-0,1953$ & 0,3372 \\
Bysra & $-0,1248$ & $-2,4028$ \\
\hline
\end{tabular}

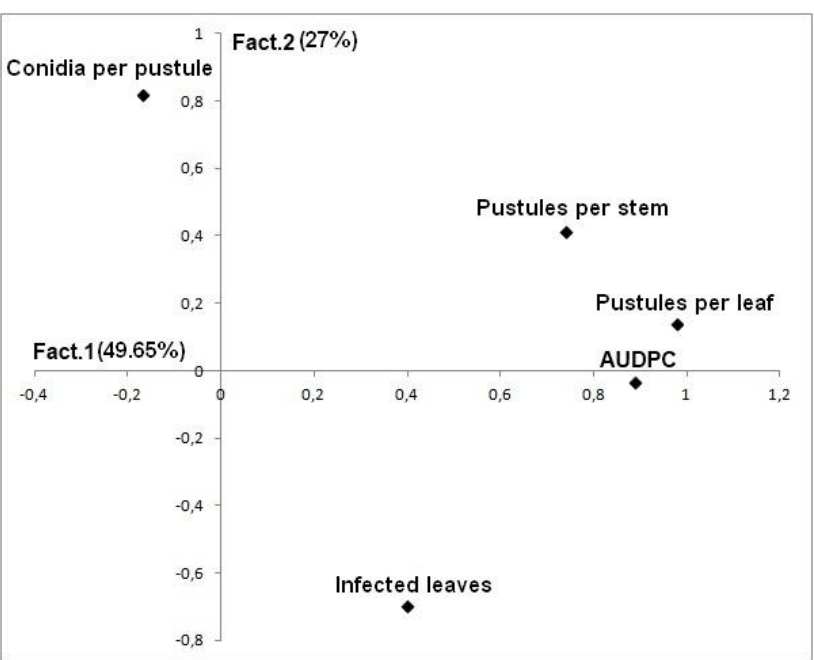

Figure 3. Cloud-point projection representing the correlation between the original variable and the principle component in the plan formed by the axes Fact.1 and Fact.2.

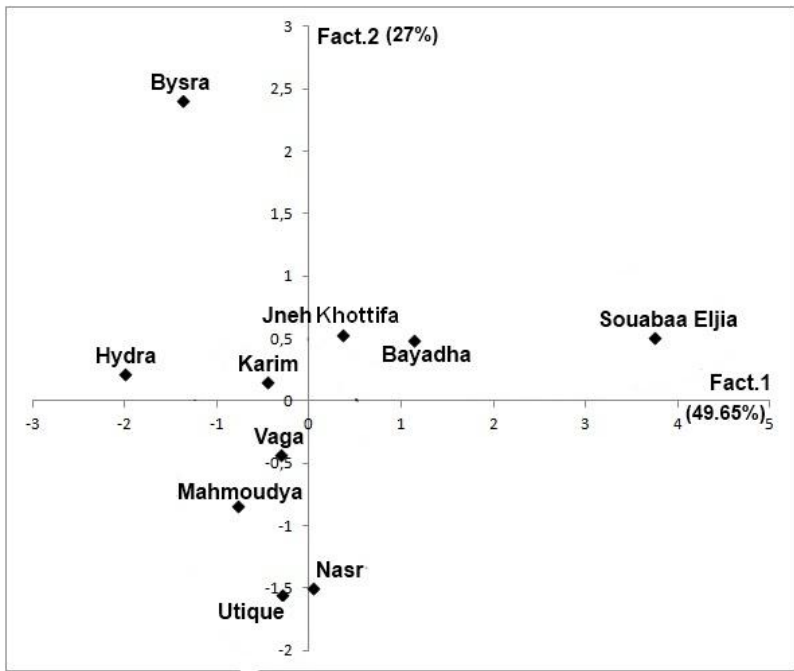

Figure 4. Cloud-point projection representing the cultivars in the plan formed by the axes Fact.1 and Fact.2.

The first group localized in the positive values of the axis Fact. 1 is characterized by a high susceptibility to the powdery mildew. It contains the durum wheat cultivars
«Jneh Khottifa», «Bayadha» and «Souabaa Eljia». The second group is characterized by a moderate susceptibility. It is formed by the durum wheat cultivars «Nasr», «Karim» and «Mahmoudya»; and the common wheat cultivars «Vaga» and «Utique». The common wheat cultivars «Hydra» and «Bysra» are isolated each one as a single group. «Hydra» is characterized by a high resistance level and «Bysra» is characterized by a moderate resistance level (Figure 2, 3).

In order to improve the hierarchical cluster analysis of populations, the matrix of Euclidean distances was calculated from the population mean scores. The clustering method applied was based on the regrouping of populations at similarity level estimated by Euclidean distances (Figure 5). Cutting the tree at distance of 40 gives five groups: Group 1 contains the most highly susceptible cultivar «Souabaa Eljia»; Group 2 formed by «Jneh Khottifa» and «Bayadha» considered as susceptible to powdery mildew. Group 3 includes the three cultivars «Karim», «Nasr» and «Utique» moderately tolerant to the disease. Group 4 includes «Mahmoudya» and «Vaga» cultivars moderately susceptible to the Bgt. The cultivars «Hydra» and «Bysra» form the highly resistant group (Figure 5).
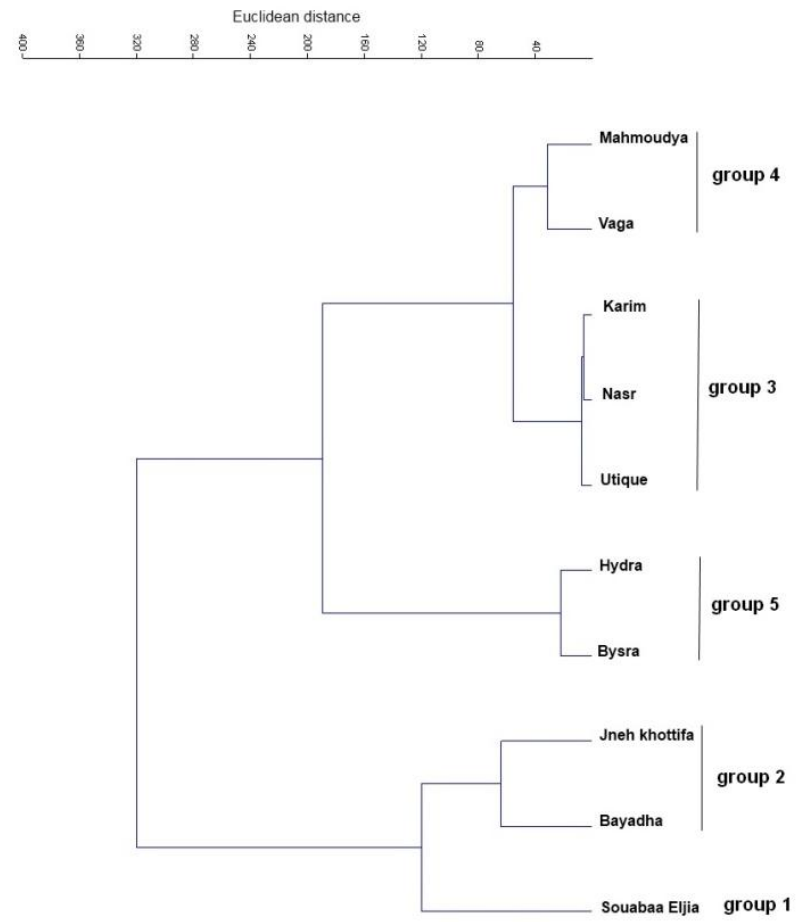

Figure 5.Hierarchical classification of the 10 cultivars based on Euclidian distances.

\section{DISCUSSION}

In this survey, there were no genotypes with effective resistance mono-gene among the cultivars tested. Real resistance to powdery mildew of all cultivars tested depended on the level of partial resistance. Partial resistance to powdery mildew is an important aim for the Tunisian wheat breeding program. Partial resistance provides long term resistance (Wang et al., 2005; Žilvinas 
and Vytautas, 2008) and allows some epidemic development of disease, but at a reduced level (Nørgaard Knudsen et al., 1986). It can be caused by alteration of one or more of the following component: increased incubation period, increased latent period, reduced infection period, reduced infection size and reduced conidium production (Kinane and Jones, 2000). It is difficult to identify race-specific resistance with quantitative and qualitative components of resistance, but it may be apparent as relatively low disease severity under high disease pressure (Žilvinas and Vytautas, 2008). Results of other researchers indicated that genotype and environment interaction exerted only a small impact on quantitative powdery mildew resistance (Tucker et al., 2007). An environmental stability could promise breeders high gain from selection of resistant lines.

Several component of resistance were observed to screen 10 Tunisian wheat cultivars, six durum wheat and four common wheat. According to these components, durum wheat showed susceptibility to natural infection of powdery mildew specially the cultivar «Souabaa Eljia» while common wheat showed resistance specially the cultivar «Hydra». Wheat cultivar may have low mildew severity either because it has partial resistance or because it has race-specific resistance effective against a large fraction of the pathogen population (Žilvinas and Vytautas, 2008). This resistance is manifested mainly in the AUDPC values calculated from the number of pustules per leaf. Reliable selecting of resistant lines is secured by continual readings of disease data in field during the growing season and if partial resistance to powdery mildew dominates, it is better to assess wheat cultivars several times during the vegetation season (Žilvinas and Vytautas, 2008). The improved durum wheat cultivars «Nasr» and «Karim» showed an intermediate reaction (Figure 2). Durum wheat is the major crop and the most widely cultivated cereal in Tunisia (Latiriet al., 2010) and is an extremely important species in Mediterranean regions, where it is the most widely grown crop and is used in the production of a wide range of end products, including semolina and pasta (Mezianiet al., 2012). Between all components of resistance tested, the number of infected leaves was nonsignificant between cultivars. The number of pustule produced on infected leaves in «Hydra»(common wheat) wassignificantly restricted compared to durum wheat cultivars (Figure 2). Kinaneand Jones (2000) reported that the percentage leaf area affected measured in field reflects the product of the mean size of the pustule and the density of pustules. They noted that «Pustule density» was the most affected component, and the only component positively correlated with field resistance. Moreover, Roderick and Clifford (1995) reported that pustule density showed a significant correlation with partial resistance in the field. «Hydra» and «Bysra» have both very low AUDPC values, but «Bysra» is having high mean number of pustules per leaf. The difference between these both cultivars could be explained by the disease evolution during the growing season. Showing low AUDPC values means that the disease progressed slightly during the growing seasons. In our case, the difference in pustules number per leaf between the first and the last reading was low in both cultivars, but «Bysra» showed higher values of this component between notations comparing to «Hydra»(data not shown). In contrast, durum lines with similar mean number of pustules per leaf as «Hydra» and «Bysra» are having a much higher AUDPC value (Figure 2).This result proves that the disease progression in durum lines was characterized by a fast-mildewing. Martin and Ellingboe (1976) reported that lento increase of powdery mildew on wheat can be caused by $p x / P m x$ interactions that result in reduced host-parasite compatibility (Gustafson and Shaner, 1982).«Hydra» and «Bysra» are not known to host Pm genes and that possibility of $p x / P m x$ interaction could be accepted as a hypothesis.

In various trials on the efficiency of multiline cultivars, spore production has been considered to evaluate disease intensity (Johnson and Taylor, 1976).In this study, 5 single pustule isolates of Bgt were collected from the most infected leaf. Isolated pustules have a large size compared to the surrounding pustules (visual estimation). The cultivar «Byrsa» had significantly higher conidia per pustule compared to the resistant cultivar «Hydra» and the susceptible cultivar «Souabaa Eljia» (Figure 2). This difference may be due to the difference in pustule size between cultivars. However, Kinaneand Jones (2000) noted that reduced conidium production per pustule could be achieved, but, without a parallel decrease in pustule size. Thus, the difference in this component between the resistance cultivar «Bysra» and the susceptible cultivar «Souabaa Eljia» could be explained by the fact that $B g t$ was stressed in the resistant cultivar compared to the susceptible. This stress was expressed by the pustule number per leaf which was significantly lower on «Bysra» compared to «Souabaa Eljia» (Figure 2). Thereby, on the susceptible cultivar, Bgt proliferate easily with an important number of pustules per leaf. Therefore, the global conidium production would be elevated but, per pustule the conidia number could be partial. In contrast, on the resistant cultivar, since the pustule number per leaf was restricted, $B g t$ needs to produce maximum conidia per pustule to ensure more likely the survival of the next generation. Johnson and Taylor (1976) mentioned that sporulation capacity could be limited by colony density. Moreover, leaf tissue on «Bysra» remained green and turgid, since pustule number per leaf was low, thus allowing photosynthesis and in result mildew growth and conidial production to prolong over a longer period of time (Abdellah et al., 2003).Difference between «Hydra» and «Bysra» concerning conidia production pr pustule could be attributed to the difference between race-specific and non-race-specific reaction to the mildew in field infection. Race-specific resistance habitually does not afford complete resistance but can cause a quantitative lessening in spores production; it could consequently slow down the rate of epidemics development (Browder, 1973) in a way analogous to that recognized to horizontal resistance (Vanderplank, 1968).Heagle and Moore (1970) pointed out that Puccinia coronata produced fewer pustules, had delayed hyphal growth and a longer latent 
period, and produced smaller pustules with fewer spores on the resistant oat cultivar Portage. Rate of Phytophthora infestans progress through leaf tissues was reported to be alike in potato cultivars King Edward, Majestic, Arran Viking, and Up-to-Date, but spores production per lesion was furthermost in King Edward and declining in Majestic, Up-to-Date, and Arran Viking (Lapwood, 1961). On «Bysra» infected leaves, global conidia production and conidia per pustule were significantly higher than that observed on «Hydra» infected leaves (Figure 2). Thus, «Hydra» is more likely to present race-specific résistance to Bgt than the cultivar «Bysra». Moreover, «Hydra» affect all component of resistance tested and seems to be more effective in restricting the efficiency of haustoria which necessary the sporulation capacity and ultimate colony size and so should reduce disease development (Carver and Carr, 1978). In addition, «Hydra» could present durable resistance to mildew. Shaner (1973) subsequent to assessment of «Knox» wheat, recognized to possess durable resistance to mildew, found that its resistance was due to the manifestation of fewer colonies (resistance to primary infection) that were undersized and less dense in conidial chains (Carver and Carr, 1978).

AUDPC values were highly correlated with the pustules number per leaf (Table 2). AUDPC integrates information (pustule number per leaf, in this case) from multiple dates into a single variable (Hammami et al., 2007). The high correlation between AUDPC and the pustule number per leaf prove that the disease progressed continuously and uniformly during the notation period. Pustule number per leaf is correlated too with the pustule number per stem (Table 2). Bgt is a foliar pathogen, but it infects stem as well. Increasing fungal biomass in the infected leaves correlated well with the reduction of maximum net photosynthesis rate which cause reductions in the amount of photosynthates produced in their foliar and stem tissues (Abdellah and Clarke, 2003). Thus, the reduction of the green blade area as a result of the increase of pustule number per leaf causes a global plant weakness, and stems could be infected as well and showed pustules manifestation.

The cluster analysis suggested that these two cultivars are genetically similar (Figure 5), but the PCA put each one in a distinct single group (Figure 4). These analyses suggest that the resistance mechanism in «Hydra» is more efficient than in «Bysra», since it affects all the tested components. The difference of the resistance mechanism could be due to the protein phosphorylation which plays an important regulatory role in the delivery and response to different biotic stress signals, and also induces a variety of stress signal-induced gene expressions (Gerber and Dubery, 2004). The cultivar «Hydra» could also affect the number of pathogen genotypes with matching virulence gene(s) that they may possibly not proliferate during the vegetation season to substantial level in the population and in turn would not enhance epidemic level of the disease. Žilvinas and Vytautas (2008) suggested that the common situation of resistance to powdery mildew is when matching virulences in the population reach a few percent, and then the fate of «efficient gene life» depends mainly on frequency of this gene in grown cultivars. This situation is present in the two resistant common wheat cultivars («Hydra» and «Bysra») since they screen a maximum of pathogen genotypes construed with a restricted pustule number per leaf, This would be true only if «Hydra» and «Bysra» have race-specific resistance that is not completely effective, or have a low frequency of matching virulence in the pathogen population.

Actually, no genotypes with effective resistance monogene among the cultivars tested could be revealed. Real resistance to powdery mildew of all cultivars tested depended more likely on the level of partial resistance. But, two common wheat cultivars («Hydra» and «Bysra») showed a high level of resistance to $B g t$ with two different reactions to the fungus, regarding specially the conidium production. «Hydra» affects all the component of resistance tested and seems more efficient than «Bysra» and could present durable resistance to mildew. More extensive studies need to be completed to understand the reaction of each cultivar to powdery mildew infection. Moreover, surveys concerning the relationships between agronomic parameters and level of resistance would be interesting and could leads to a genetic analysis of $B g t$ infection response.

\section{LITERATURE CITED}

Abdellah, A. and D.D. Clarke. 2003. Relative tolerances of wild and cultivated barleys to infection by Blumeriagraminisf. sp. hordei (Syn. Erysiphegraminisf. sp. hordei). I. The effects of infection on growth and development. Physiological and Molecular Plant Pathology 62: 237-250.

Abdellah, A., Donald, D., Clarke, P. and J. Dominy. 2003. Relative tolerances of wild and cultivated barley to infection by Blumeriagraminisf.sp. hordei (Syn. Erysiphegraminisf.sp. hordei).The effects of infection on photosynthesis and respiration.Physiological and Molecular Plant Pathology6: 347-354.

Browder, L. E. 1973. Specificity of the Pucciniarecondita:Triticumaestivum 'Bulgaria 88' relationship. Phytopathology. 63:524-528.

Carver, T.L.W. andA.J.H.Carr.1978. Effects of host resistance on the development of haustoria and colonies of oat mildew. Ann. Appl. Biol. 88 :171-178.

Daaloul, A. 1986. Recherches agronomiques sur les céréales en Tunisie : situation actuelle et perspectives. In Lerin F. (Eds) Céréales et produits céréaliers en Méditerranée. Montpellier: CIHEAM-IAMM p. 119-123 : réf. (Options Méditerranéennes :Série Etudes).

De Curtis, F.,Spina, A.M., Piedimonte, D., Lima, G. and V.D. Cicco.2007. Biological and integrated control of wheat powdery mildew.J. Plant Pathol.89 (4) p. S38

Filippo, D.C.,Vincenzo,D.C. and L.Giuseppe.2012.Efficacy of biocontrol yeasts combined with calcium silicate or sulphur for controlling durum wheat powdery mildew and increasing grain yield components. Field Crops Res. 134: 36-46.

Friedrich, F., Martin, S. and S.Gerd. 2010. Sensitivity of Wheat Powdery Mildew (Blumeriagraminisf.sp. tritici) towards Metrafenone. GesundePflanzen. 62: 29-33. DOI 10.1007/s10343-010-0214-X.

George, P.E.B., Hunter, J.S. and G.W. Hunter. 2005. Statistics for experimenters; Design, Innovation, and Discovery. $2^{\text {nd }}($ Eds).Wiley Series in Probability and Statistics. Established by Walter A. Shewhart and Samual S. 
Wilks.Wiley-interscience. A John Wiley \& Son, INC., Publication.

Gerber, I.B. andI.A. Dubery.2004. Protein phosphorylation in Nicotianatabacum cells in response to perception of lipopolysaccharides from Burkholderiacepacia. Phytochemistry 65: 2957-2966.

Griffey, C.A., Das, M.K. and E.L. Stromberg.1993. Effectiveness of adult-plant resistance in reducing grain yield loss to powdery mildew in winter wheat. Plant Dis. 77: 618-622.

Gustafson, G.D. andG.Shaner.1982. Influence of plant age on the expression of slow-mildewing resistance in wheat. Phytopathology. 72:746-749.

Hammami, I., Allagui, M.B., Chakroun,M. and M.El Gazzeh.2007. Evaluating landrace oats (Avena spp.) collected in Tunisia for crown rust resistance under natural infection. Euphytica. 157:27-34.

Heagle, A.S., and M.B. Moore, 1970. Someeffects of moderate adult resistance to crownrust of oats.Phytopathology. 60:461-466.

Johnson, R. andA.J.Taylor.1976. Spore yield of pathogens .in investigations of the racespecificity of host resistance. Annu. Rev. Phytopathol. 14: 97-119.

Kinane, J.T. andP.W. Jones.2000. Components of partial resistance to powdery mildew in wheat mutants. European J. of plant pathology. 106: 607-616.

Lapwood, D.H. 1961. Potato haulmresistance to Phytophthorainfestans.II. Lesion production and sporulation.Ann. Appl. Biot.49:316 -30.

Latiri, K.,Lhomme, J.P., Annabi, M. andT.L. Setter.2010. Wheat production in Tunisia: Progress, inter-annual variability and relation to rainfall. Europ. J. Agronomy 33: 33-42.

Maamouri, A. and M. El Faleh. 1983. Variétés de céréales recommandées en Tunisie. - Documents techniques : INRAT N 87.

Mladenov, V., B. Banjac, M. Milošević. 2012. Evaluation of yield and seed requirements stability of bread wheat(Triticumaestivum L.) via ammi model. Turkish J. of Field Crops. 17(2): 203-207

Martin, T.J. andA.H.Ellingboe. 1976.Difference between compatible parasite/host genotypes involving the Pm4 locus of wheat and the corresponding genes in Erysiphegraminisfsptritici. Phytopathology. 66: 1435-1438.

Meloun, M.,Militký, J. and M.Forina. 1992.Chemometrics for Analytical Chemistry, Volume 1: Pc-Aided Statistical Data Analysis, Ellis Horwood, Chichester, 330 Stran, Isbn 0-13126376-5.

Meziani, S., Nadaud, I., Gaillard-Martinie, B., Chambon, M. Benali, M. and G. Branlard.2012. Proteomic analysis of the mature kernel aleurone layer in common and durum wheat. J. of Cereal Science. 55: 323-330.

Na Liu.,G.Guoshu, G., Min, Z., You, Z. Zhixiang, C., Jizhi,Y., Huabao, C.,Xuegui, W., Yu, L. and L. Kai.2012. Oversummering of wheat powdery mildew in Sichuan Province. China. Crop Protection. 34: 112-118.

Nørgaard Knudsen, J.C., Dalsgaard, H.H. and J. Helms..1986. Field assessment of partial resistance to powdery mildew in spring barley. Euphytica35: 233-243.

Pena, R.J. 2007.Current and future trends of wheat quality needs. In: Buck, HT, Nisi JE, Salomon N (Eds.). Wheat production in stressed environments. Springer.p: 411-424.

Rezgui.M., BenMechlia, N., Bizid, E., Kalboussi, R. andR. Hayouni.2000. Etude de la stabilité du rendement de blé dur dans différentes régions de la Tunisie .In (C. Royo, M.M. Nachit, N. Di Fonzo, J.L. Araus, Eds.) Durumwheatimprovement in the Mediterraneanregion: New challenges $=$ L'amélioration du blé dur dans la région méditerranéenne : Nouveaux défis. Zaragoza :CIHEAMIAMZ 2, p. 167-172.

Roderick, H.W. andB.C. Clifford.1995. Variation in adult plant resistance to powdery mildew in spring oats under field and laboratory conditions. Plant Pathology 44: 366-373.

Ruth, E. andH.Ralph.2008. Accommodation of powdery mildew fungi in intact plant cells. J. of Plant Physiology 165: 5-18.

Shaner, G. 1973.Evaluation of slow mildewing resistance of Knox wheat in the field.Phytopathology.63:867-872.

StatSoft. 2001. Statistical for Windows (Computer Program Manual). Tulsa. Oklahoma. USA. 623 pp.

Tucker, D.M., Griffey,C.A. Liu, S., Brown-Guedira, G.L., Marshall,D.S. and Saghai-Maroof, M. 2007. Confirmation of three quantitative trait loci conferring adult plant resistance to powdery mildew in two winter wheat populations.Euphytica 155: 1-13.

Vanderplank, J.E. 1968.Disease Resistancein Plants. New York \& London:Academic. 206 pp.

Wang, Z.L., Li, L.H., He, Z.H.,.Duan, X.Y , Zhou, Y.L., Chen, X.M., Lellimo, M., Singh,R.P. , Wang,H. andX.C. Xia. 2005. Seedling and adult plant resistance to powdery mildew in Chinese bread wheat and lines. Plant Disease89: 457-463.

Zhang, K., Zhao, L. ,Hai, Y., Chen, G. andJ. Tian. 2008. QTL mapping for adult-plant resistance to powdery mildew, lodging resistance, and internode length below spike in wheat. ActaAgronomicaSinica. 34(8): 1350-1357.

Žilvinas, L. andR. Vytautas.2008. Powdery mildew resistance of winter wheat cultivars registered in Lithuania. ZemdirbysteAgriculture. 95 (3):327-335 UDK 633.11:632.482.112. 